\title{
Effective EFL Instruction in the Vietnamese Context: From Beliefs to Actual Classroom Practices
}

\author{
Nga Thi Tuyet Phan \\ PhD, Lecturer, Faculty of Foreign Languages, Industrial University of Ho Chi Minh \\ city, Ho Chi Minh city, Vietnam, ngaphan2004@gmail.com
}

This study was designed to extend our knowledge of the differences between EFL teachers' beliefs of effective instruction and their actual classroom practices under the influence of different factors in the Vietnamese context. The paper took a qualitative approach using focus group discussion, journaling, non-participant observation and post-observation individual interviews as data gathering tools. Findings from this study indicate a wide gap that existed between what was believed and what was actually implemented by experienced teachers. Participating teachers valued and were actually aware of the benefits of interactive activities to students' communication skills. However, they adopted teacher-centred, GTMoriented instruction in the classroom. The study teachers' perceptions of students' factors, traditional educational values and norms, physical working constraints, family roles and emotion appeared to affect their teaching practices in the classroom. This research has the potential to inform teacher development in Vietnam and in similar settings with the view to improving the quality of English teaching and learning.

Keywords: teachers' beliefs, classroom practices, EFL settings, educational values and norms, emotion, Vietnam

\section{INTRODUCTION}

In Vietnam, the English language has been given a special place, especially after the country decided to expand relations with many foreign countries in the 1980s. The significant importance of English in Vietnam is recognized in society and within every family (Phan, 2015; Nguyen, 2013). Many Vietnamese parents believe that their children would be deprived of opportunities for employment if they do not have the ability to communicate fluently in English. The Government of Vietnam has strongly supported and strengthened this societal need for English learning in Vietnam. The government has mandated a number of important policies concerning teaching and learning English at elementary, secondary and higher education. At present, university students are required to take English for their graduation exams. Anyone wanting to

Citation: Phan, N. T. T. (2018). Effective EFL Instruction in the Vietnamese Context: From Beliefs to Actual Classroom Practices. International Journal of Instruction, 11(3), 403-418. https://doi.org/10.12973/iji.2018.11328a 
pursue further studies (e.g. postgraduate programmes) must obtain an English certificate. English becomes a compulsory school subject from grade 3 and all learners at every educational level in 2020 are expected to be capable of speaking English fluently. However, in contrast to the investment into English learning of the government and society, the poor quality of teaching and learning English in different language class settings has been highlighted in a number of papers (Phan, 2015; Nguyen, 2013). Accordingly, several efforts have been made into improving the low English efficiency levels of language learners and teachers' professional knowledge and skills.

Teachers' beliefs have profound impacts on various aspects of language teaching and learning because these beliefs shape their classroom practices, their students' perceptions about learning and learning achievement (Barrot, 2016; Farrell \& Bennis 2013). In the academic literature, much research has focused on teachers' beliefs in language teaching and their classroom behaviours and the differences between pedagogical beliefs and practices among expert and novice teachers. Yet, there has been little previous research on these issues in EFL settings (Borg, 2009). In the Vietnamese context, some studies have investigated the effectiveness of teachers' implementation of certain teaching methods in the Vietnamese English as a Foreign Language (EFL) classrooms (Nguyen, 2013; Tomlison \& Dat, 2004), factors contributing to teachers' adherence to traditional teaching approaches (Le, 2011; Phan, 2015), or student motivation (Phan, 2011). However, what has not been established much in this context is whether university EFL teachers teach in accordance with their beliefs and factors underpin their practices. Therefore, this study was designed to extend our knowledge of the differences between EFL teachers' beliefs of effective instruction and their actual classroom practices under the influence of different factors. This research has the potential to inform teacher development in Vietnam and in similar settings with the view to improving the quality of English teaching and learning. The study addressed the following questions:

Q1. Do the teaching beliefs of effective instruction of Vietnamese EFL teachers run consistent with their classroom practices?

Q2. What are the factors that cause the congruity/incongruity?

\section{LITERATURE REVIEW}

\section{English Language Teaching approaches}

According to some researchers (Brown, 2007; Fotos, 2005; Richards \& Rogers, 2001) the most widespread EFL teaching approaches in EFL contexts in general and in Vietnam in particular are likely to be the Grammar-Translation Method, Communicative Language Teaching and Task-Based Language Teaching. The following sections review these approaches.

\section{The Grammar Translation Method}

Compared to Communicative Language Teaching (CLT) and Task- Based Language Teaching (TBLT), the Grammar-Translation Method (GTM) has the oldest history and was the main foreign language teaching approach from the 1840s to the 1940s (Fotos, 2005; Richards \& Rogers, 2001). Still being used in EFL contexts in the present day, 
e.g. in Vietnam, the method is known to focus on rote memorizing of grammar rules, vocabulary, syntax, and morphology and on translating texts into and out of the target language. In a class where the GTM is being applied, the use of the mother tongue dominates that of the target language. Teachers typically use structural syllabuses in such a classroom (Fotos, 2005). The unit of teaching and practice is the word or sentence. Much class time is devoted to explaining grammar rules and vocabulary items in isolation. Vocabulary and grammar learning are deductively and systematically drawn from reading texts. Pronunciation and communicative activities are largely ignored. Instead, reading and writing are prioritised. Teachers in GTM classes highlight accuracy (Brown, 2007; Fotos, 2005; Richards \& Rogers, 2001). For these reasons, the GTM has long been criticised for its failure to help learners develop their communicative ability which is considered to be critical in a global society (Brown, 2007; Fotos, 2005). Language learners are passive in the classroom. Most of their needs are ignored and teachers are regarded as an authority. Besides, there is little student-student interaction, and it is often teachers who initiate interactions.

\section{Communicative Language Teaching}

CLT is a language teaching approach that develops learners' communicative competence rather than linguistic competence (see Richards and Rogers (2001) for an explanation). CLT is believed to provide learners with skills to communicate in contexts outside the classroom. For this reason, CLT tries to link classroom language learning with real-life activities, and emphasises learning through interaction and the use of authentic materials. In a CLT classroom, fluency, not accuracy, is the focus of attention. Learners are engaged in "the pragmatic, authentic, functional use of language for meaningful purposes" (Brown, 2007, p.43) through teachers' use of cooperative activities, pair work and group work, and real-life content materials which are relevant to learners' needs. Classroom activities are designed to include four language skills: listening, speaking, reading and writing, but using the skills in ways which set up conditions for students' sharing and negotiation of meaning is the focus of CLT (Richards \& Rogers, 2001, p. 165).

Richards and Rogers (2001) provided a list of roles for teachers and learners within the CLT approach that the GTM lacks (pp. 166-168). Teachers are no longer knowledge authorities. They do not control classroom activities but function as persons with multiple roles in the language learning process. Some of these new roles include facilitator, needs analyst, counsellor, group process manager, resource provider and learner. Besides, learners' active roles are highly valued in the CLT approach. They are encouraged to bring their unique knowledge background and learning styles into the negotiation of meaning. It is often learners, not teachers, who initiate interactions. CLT seeks to promote cooperation among learners and between teachers and learners. It appears that CLT aspires to provide more opportunities than the GTM for teachers and learners to generate language actively and creatively.

Tasked-based Language Teaching

Task-based Language Teaching (TBLT) is the latest methodological realisation of CLT. It too is within a communicative framework and targets learners' communication ability 
(Littlewood, 2007, p. 243). In the literature, it is generally agreed that TBLT and CLT share general assumptions about the nature of language and language learning. For example, TBLT also focuses on real communication, meaningful tasks and meaningful language (Richards \& Rogers, 2001). However, although TBLT is a family member of CLT, it has some distinctive features. First, within the TBLT approach, a task serves as a major component, "a central unit of planning and teaching" (Richards \& Rogers, 2001, p.224). A classroom activity is a task when it has a primary focus on meaning, some concern for form, and a clearly defined communicative outcome (Ellis, 2003, pp.9-10). Second, a central tenet of a task-based approach is a need to focus on form. In TBLT, linguistic forms are focused on by students incidentally during the process of task completion (Ellis, 2003). Knowledge of form is developed through interaction and the negotiation of meaning. Students tend not to be explicitly instructed about linguistic forms but, in order to complete tasks, they should have to make use of these forms (Ellis, 2003; Richards \& Rogers, 2001).

Because TBLT and CLT are under the same umbrella of communicative pedagogy, the general roles of teachers and learners in TBLT classrooms overlap with those in CLT classrooms. In addition, because TBLT focuses on task outcome, teachers and learners require some additional roles. Teachers need to select and sequence tasks, prepare learners for tasks, and raise learners' consciousness of certain linguistic items through designing conditions for learners to notice language form. Learners may need to adapt to greater frequency of pair work and small group work, pay attention to both meaning and linguistic form, and make use of available language resources to complete tasks (Richards \& Rogers, 2001, pp. 235-236).

\section{Selected studies on teachers' beliefs and practices}

According to Borg (2003), teachers' beliefs are referred to as what teachers know, believe, and think. Because teachers' beliefs are not directly observable, they are neither easy to define nor study. Teachers' knowledge and beliefs have been the focus of previous investigations (e.g., Barrot, 2016; Cheng \& Moses, 2011; Rahman, Kaur \& Pandian, 2018). Attention has been paid to the congruity-incongruity/consistencyinconsistency of experienced ESL/EFL teachers' pedagogical beliefs and practices. However, these studies have yielded inconsistent results.

Many researchers examine the beliefs and practices of experienced teachers and posit that expert teachers' beliefs are generally stable and consist of tacitly held assumptions and perceptions (Alghanmi \& Shukri, 2016; King \& Nash, 2011; Kuzborska, 2011, Mori, 2011; Phan, 2004; Yang \& Gao, 2013). Experienced teachers both teach according to their pedagogical beliefs, and acknowledge that these beliefs shape their actual classroom instruction and their students' perceptions about learning. For example, Alghanmi and Shukri (2016) conducted a study with 30 teachers in Saudi Arabia to understand their beliefs and practices related to English grammar instruction. They found that teachers' beliefs were significantly reflected in their classroom practices. Kuzborska (2011) confirmed teachers' congruence between their beliefs and practices in the teaching of reading to advanced learners in a Lithuanian university. Findings indicated that teachers' classroom behaviours reflected their beliefs about skills-based 
approach to reading instruction, emphasizing vocabulary, reading aloud, translation, and whole class discussion of texts. King and Nash (2011) in their qualitative study using observation and collection of artefacts found that participants' pedagogical decisions arose from their beliefs or assumptions about culturally and linguistically diverse students and families, classrooms, and materials to be taught. Similarly, in a study of Phan (2004) in the Vietnamese context, two female university teachers expressed their positive views towards CLT. The teachers valued the importance of using CLT in the language classroom to promote students' grammatical competence. How the teachers helped their students in class is an accurate reflection of what they believed.

However, some researchers disagree that expert teachers' beliefs run consistent with their practices (Baleghizadeh \& Farshchi, 2012; Ferreira, 2014; Hos \& Kekec, 2014; Rashidi \& Moghadam, 2015; Zheng \& Borg, 2014). For example, Barrot (2016), in a study with experienced ESL teachers in Malaysia, discovered some inconsistencies between the teachers' beliefs and practices. All the teachers were aware of and agreed with the concept of self-assessment, multiliteracy, differentiation and reflective learning but they failed to fully practise such teaching principles in their classrooms. Hos and Kekec's (2014) findings supported the inconsistency between teachers' beliefs and practices. Although many of the teachers in their study believed that CLT would be the best method to teach grammar, they did not make use of it in their classrooms. Grammar was generally taught in isolation and deductively rather than contextually. Similarly, Baleghizadeh and Farshchi (2012) found that formal instruction, the use of grammatical terminology, and explicit grammar teaching were valued by EFL teachers in Iran although the majority of the respondents believed in inductive, implicit, problem solving activities, and presentation through authentic texts. Rahman, Kaur and Pandian (2018) also reported an incongruity between what teachers verbally reported and their classroom behaviours relating to CLT. Teachers supported integrated form and focusoriented teaching, communicative work, student-centred classroom in their interviews. However, observation data indicated that teachers tended to employ activities that were forms-focused, and conducted classroom activities in a non-communicative fashion.

Several factors were found to be responsible for why conflicts between beliefs and practices exist. Previous studies (e.g. King \& Nash, 2011; Rahman, Kaur \& Pandian, 2018; Le, 2011; Nguyen, 2013) have listed reasons for the belief-practice mismatch, including (a) teachers' factors: Education programs, teacher motivation, personalities, emotion, prior teaching experiences, life experiences, experiences of cultural or linguistic differences; (b) students' factors: Knowledge background, motivation, learning strategies; (c) other factors: Course objectives, curriculum, available materials, setting. Because the belief-practice relationship is affected by a number of factors, it remains complex and therefore deserves further research.

The brief review above has pointed out the contradictory results regarding teachers' belief-practice relationship and the complex nature of the belief-practice relationship. Because a relatively few studies have been carried out in university EFL contexts such as Vietnam although the number is increasing, it is necessary to conduct a research 
investigating teachers' beliefs of effective EFL instruction and their actual classroom behaviours in order to figure out any conflicts as well as underpinning reasons.

\section{METHOD}

The study took the form of a qualitative case study because qualitative studies support the view that knowledge is constructed out of on-going human interactions and is developed within a social context (Creswell, 2012). The aim of the study is to understand the relationship between EFL teachers' beliefs of effective instruction and their actual classroom practices at a university in Vietnam. These perceptions and teaching behaviours were negotiated socially and historically through participants' interactions with their teachers at high school or college, with their family members, with students, colleagues and university leaders. Case study design was adopted for the present study because qualitative case studies allow researchers to understand a case in depth and within its context. Qualitative case studies take participants' perspectives and experiences as central, explore the complex interactions of factors and report multiple perspectives (Stake, 2010).

\section{Research context}

The technical university where the study was conducted is situated in the busiest city of Viet Nam, Ho Chi Minh City. The university provides both industrial and economics training services from university degrees, in-service degrees to vocational certificates. The researcher selected participants from Faculty B where she had been employed to work as an EFL teacher. The process of approaching and selecting participants was facilitated by the researcher's established relationships with colleagues and leaders at the university and faculty. Six faculty members, one male and five female, were invited to participate in the study. They were provided information on the purpose of the study and research protocol.

Participating teachers teach General English and IELTS for students who have failed the university entrance exam to any other universities and subsequently register at one of three joint-programmes: Business Administration, Information Technology, and Accounting and Auditing. The participating teachers' age ranged from 30 to 42 . The years of teaching experience ranged from 7 to 17 years. All teachers have earned Master's Degrees in TESOL from different universities in Vietnam. The teachers were labelled by numbers for the sake of confidentiality (i.e. Teacher 1 -Teacher 6).

Table 1

Profiles of 6 EFL teachers

\begin{tabular}{llllll}
\hline Teacher & Gender & Age & $\begin{array}{l}\text { Approx. years } \\
\text { of teaching }\end{array}$ & Qualification & $\begin{array}{l}\text { Main skill(s) } \\
\text { taught }\end{array}$ \\
\hline Teacher 1 & Female & 30 & 7 & BA in TEFL, MA in TESOL & Reading/ Writing \\
\hline Teacher 2 & Female & 34 & 11 & BA in TEFL, MA in TESOL & Writing/Listening \\
\hline Teacher 3 & Female & 35 & 12 & BA in TEFL, MA in TESOL & Listening \\
\hline Teacher 4 & Female & 38 & 16 & BA in English, MA in TESOL Writing \\
\hline Teacher 5 & Female & 36 & 13 & BA in TEFL, MA in TESOL & Writing/Speaking \\
\hline Teacher 6 & Male & 42 & 17 & BA in TEFL, MA in TESOL & Reading \\
\hline
\end{tabular}




\section{Data collection tools and procedures}

In the study, focus group discussion, journaling, non-participant observation and postobservation individual interview were employed as research tools. Focus group discussion facilitated participation and interpersonal communication and encouraged a supportive environment. Journaling helped the researcher keep track of and understand each participant's perspective on significant events and experiences in their own words. Observation served as a basis for certain interview questions and enabled the researcher to contextualize findings based on interviews and reflective journaling. Non-participant observation was chosen because a complete observer does not interfere with people or activities under observation (Creswell, 2012, p. 214). Post-observation individual interviews offered participants opportunities to elaborate on what they revealed previously.

Participating teachers were first invited to a focus group discussion where they expressed their views of effective EFL instruction, effective EFL teachers and the local teaching context.The focus group discussion lasted approximately 60 minutes and it was audio recorded. The teachers were then observed in their classrooms over three weeks and invited to keep entries after their lessons over this period. In their journal entries, study teachers were encouraged to describe their lessons or write about things that affected their teaching. The teachers were interviewed after the last classroom observation. During interviews, teachers were invited to explain for certain classroom behaviours. They were also encouraged to talk about things that contributed to successful lessons or caused unsuccessful teaching experiences. Each semi-structured interview lasted about 30 minutes and was audio recorded. Notes were taken during interview and observation sessions. The preferred language to communicate between the researcher and the participants and within the participants was Vietnamese although the teachers had the option of using English.

\section{Data analysis techniques}

To analyse data, an inductive coding process (Creswell, 2012) and thematic analysis (Braun \& Clarke, 2006) were used. The goal of themetic analysis is to identify themes, i.e. patterns across data sets that are important to the research. According to Braun and Clarke (2006), a theoretical thematic analysis driven by the specific research question(s) and/or the analyst's focus is an effective way to analyse qualitative data. A six-step guide is suggested to do the analysis, including becoming familiar with the data, generating initial codes, searching for the themes, reviewing themes, defining themes and writing up.

In the present study, data analysis began with taking notes during or immediately after focus group discussions, observation and interviews and through the entire research process. The researcher transcribed the recording right after an interview, a focus group discussion or an observation session. Transcripts of focus group discussion, interview, and observation were coded and analysed along with journal entries and the researcher's journal. Findings from different sources were validated through a triangulation process (Lincoln \& Guba, 1985). Recordings were checked against the transcripts before being 
sent back to participants to add or change information. The transcripts and journal entries were scanned repeatedly for recurring themes. The study used four different types of research instrument: focus group discussion combined with journaling, observation and interview. The multi-method triangulation helped to increase the amount and nature of data gained from participants. The researcher's translations of transcripts into English were cross-checked.

The researcher coded for specific research questions to identify themes in this study. First, each transcript of an individual teacher's interviews or each journal entry was read through several times until I got familiar with its content. I read the document line-byline and looked for words, phrases, sentences, or whole paragraphs that related to my specific research question. I then searched, cut and pasted chunks of data related to this concern within a data source, for example, an interview, and then repeated the process with another data source. When I got all chunks of data related to this specific concern throughout all my data sources, I started coding. Initially, my codes were participants' actual words, phrases or my summary of their ideas. I listed all the codes in the margin. I did not code every sentence because I was unable to process too many codes. In the next step, I grouped similar codes together, reduced overlapping or redundant codes and ended up with a manageable number of codes. Each major category now consisted of several sub-categories. After I had the categories and sub-categories for each teacher, I reviewed and collated individual teachers' sub-categories and categories with those of other teachers. I used tables to look for similar or different patterns among teachers. Table 2 provides one example of how individual teachers' emerging categories were compared among teachers.

Table 2

Teachers' perceptions of effective EFL instructions

\begin{tabular}{cllll}
\hline Teacher & $\begin{array}{l}\text { Relevant } \\
\text { activities }\end{array}$ & $\begin{array}{l}\text { Activities } \\
\text { promoting students } \\
\text { active roles }\end{array}$ & $\begin{array}{l}\text { Communicative } \\
\text { activities }\end{array}$ & $\begin{array}{l}\text { Warm-up } \\
\text { activities/games }\end{array}$ \\
\hline 1 & $\sqrt{ }$ & $\sqrt{ }$ & $\sqrt{ }$ & $\sqrt{ }$ \\
\hline 2 & $\sqrt{ }$ & $\sqrt{ }$ & $\sqrt{ }$ & $\sqrt{ }$ \\
\hline 3 & & $\sqrt{ }$ & $\sqrt{ }$ & $\sqrt{ }$ \\
\hline 4 & $\sqrt{ }$ & $\sqrt{ }$ & $\sqrt{ }$ & $\sqrt{ }$ \\
\hline 6 & $\sqrt{ }$ & & $\sqrt{ }$ & $\sqrt{ }$ \\
\hline
\end{tabular}

\section{FINDINGS}

Based on the class observation and journaling data, it is seen that teachers' classroom practices were totally different from their stated beliefs.

\section{Teachers' perceptions of effective EFL instructions}

Data show that six teachers in the study had their own construction of effective instruction emerging from both their learning and teaching experiences and education background. In the teachers' views, effective instruction was to facilitate students' communicative ability and engender their engagement or motivation in the classroom. 
The teachers also described how an effective teacher structured classroom activities to activate the active roles of students. It seems that participating teachers' subscribed-to effective ELT approaches were consistent with tenets of the communicative pedagogy.

In describing different techniques and activities an effective EFL teacher should use in the classroom, the teachers mentioned activities which offered opportunities for students to communicate in the target language and to practise the target language outside the classroom. The activities the effective EFL teacher offered in the classroom should also be related to students' backgrounds and needs in order to engage the students' participation. The inclusion of as many communicative activities where students could communicate in English as possible helped students "negotiate meanings with classmates", "understand foreigners" and "find employment" in the future. The effective teacher "tailored activities to meet students' current levels of proficiency", "added more detailed questions into existing textbook activities", or "included his/her own activities" beside textbook tasks.

Study teachers also stated that an effective teacher encouraged students to take risks, to lead active roles in the classroom and to take responsibility for their own learning. The effective teacher "put an emphasis on student contribution to activity design and selection", "invited students to participate in the process of designing learning activities", "encouraged students to discuss with teachers what they would like to study", and "introduced new knowledge" that students had never encountered to make the learning activities more challenging.

Moreover, according to these study teachers, an effective teacher in the language classroom used warm-up activities or games to arouse students' curiosity and/or help them relax, thereby encouraging them to participate in the activities and other subsequent activities. Participating teachers mentioned the usefulness of videos, songs, crosswords, grammar-review quizzes or vocabulary review quizzes to relax students, and to encourage them to think that learning is fun. The teachers also mentioned the 'positive' learning atmosphere that such activities brought about.

\section{Teachers' actual classroom practices}

Observation and journaling data show that the teachers had a strong inclination towards the GTM although they did not perceive it as an effective EFL approach during the focus group discussion. In observed lessons and descriptions of effective lessons, all the teachers used the same techniques and strategies to organise classroom activities. Minimum use of English, context-free explanation of discrete grammar and vocabulary items and error focus were frequently used techniques. It seems that teachers' primary concern was to complete textbook tasks, rather than developing students' communicative ability. Therefore, study teachers generally brought teacher-controlled activities to the classrooms.

Six teachers in the study stated that verbal and written feedback, that is, teachers' responses to students' mistakes and errors during and after an activity, played a key role in helping their students improve English proficiency. However, these teachers relied on explicit, immediate feedback and expressed their concern for controlling accuracy at 
every step of learning by interrupting their students to provide corrective feedback. They then provided answer keys at the end of every learning activity and were conscious of giving detailed explanations. For example, in one of her journal, teacher 5 described how she provided feedback:

I check every learner's mistakes: grammatical mistakes and pronunciation mistakes. If most students have the same mistake, I will correct that mistake in front of the whole class. I show them why it is wrong. I give a lot of examples. I call several students to practice this particular mistake in different sentences until they can write correctly. I also re-write students' sentences.

Observation sessions of teacher 5's speaking lessons confirmed that she paid special attention to students' linguistic mistakes. She tended to interrupt her students to provide corrective feedback on every pronunciation or grammar mistake but she gave no comments on the content or organization. Her feedback was detailed and repetitive. It seems that the teacher did her utmost to draw students' attention to mistakes in order to reinforce memory.

All teachers in the study focused largely on explicit presentation of discrete points of grammar knowledge and vocabulary items that were found in the texts or were required to use in subsequent activities. For example, in one observed writing lesson, teacher 1 first provided a generalized linguistic form on board, which was: "S + have/has + V-ed regular + O". She proceeded with an explanation of the usage of the structure in Vietnamese. She then asked her students to underlie all grammatical structures in a writing model in the writing textbook. The teacher also provided her students with translation exercises which were also from the textbook. The students were given only one opportunity at the end of the lesson to do their own writing. Previously-learntstructures were expected to appear in students' own writing of individual, isolated sentences as evidence of their understanding of the instruction.

In all study teachers' observed classrooms, there was a minimum use of the target language in the classroom discourse. Four teachers used Vietnamese instead of English to deliver basic classroom instructions while the other two used English first and provided Vietnamese translations immediately after. All teachers used far more Vietnamese than English to present new knowledge of the lessons, to provide feedback or explanations. Teachers gave students opportunities to read the texts aloud in the target language. When students had a chance to speak, they frequently asked: "Can we answer the question in Vietnamese, please?"

\section{Factors influencing teachers' actual classroom practices}

The rationale behind teachers' classroom practices was revealed in the post-observation interviews conducted with individual teachers and in their journal entries. Findings suggest that the study teachers' perceptions of students' factors, traditional educational values and norms, physical working constraints, family roles and emotion affected their teaching practices in the classroom.

The teachers stated that students with little motivation and low ability hindered their implementation of communicative activities. Teacher 1 said that she could not 
implement pair work or group work in classrooms of low-achieving students. It was "a waste of time" so she tried to follow syllabus guidelines and "finish[ed] as many exercises as possible". Teacher 2 said that her students in weak classes had fewer opportunities to participate in some activities such as "interviewing" in order to "increase communication ability" because she "spent more time explaining". She highlighted that some students "did not know a word in English", and that the students "did not have enough vocabulary to understand text-book instructions" or "[couldn't] learn by heart some English expressions". Consequently, the teacher "just provided short, concise explanation" and "grammatical structures".

It is also due to students' low ability that participating teachers said that they mainly used Vietnamese and not much English in their classrooms. Study teachers all emphasized students' comprehension difficulties if the teachers used more English in the classroom. Teacher 3 used the metaphor, "they [students] will swim in an ocean of English words and knowledge" to describe the challenge students might face. Teacher 5 described students' behaviour while she was lecturing in English in one classroom in the following way: "Play[ing] games", "discuss[ing] something else", "teas[ing] one another" since the students did not understand the content of the lesson.

Study teachers reported that long-standing education norms made them uncertain about any significant effect of communicative activities on students' knowledge and skills. Many high-school teachers and students were familiar with old teaching practices, which made it impossible for the study teachers to implement interactive practices. In addition, an achievement-oriented culture contributed to the prevalence of such old methods. Parental expectations of their children passing tests with good marks were a factor that encouraged both teachers and students to work very industriously on tests. Teacher 1 stressed that "students cannot speak in English despite learning the language for six years or more at school" and that this was a result of a focus on "grammar rules, memorizing and repetition" and "teaching-to-the test practice". Teacher 6 stated that an achievement-oriented culture created a pressure for EFL teachers, including him, to teach test-taking skills rather than helping students to better their communication skills.

The teachers also considered the syllabus time-frame, class size and student groupings as obstacles to the implementation of the communicative pedagogy. For example, teacher 1, 2 and teacher 5 felt constrained by the syllabus time-frame, saying that they did not have enough time to "explain all important points" specified in the syllabus, to "support students' comprehension" of the lessons or to "check students' work carefully". All teachers claimed that fifty students in a classroom were "too much to teach communicatively". Teacher 5 complained that it was difficult for her to "keep all students in order and be attentive to [his] talk". Teacher 4 and 6 wrote that they "[could] not provide help to many students, especially struggling ones" when the number of students was around fifty.

Family roles were also another important factor that prevented five female study teachers from teaching EFL communicatively as they perceived. For example, teacher 3 stated that she would "do much better", her teaching activities would be "more flexible and suitable to students" if she was not "constrained" by "household chores" and if 
"[her] thoughts were not interrupted" by her children. Teacher 4 stated she did not have time preparing for her next lessons since she "[had] to do two duties [teaching and taking care of children] at the same time". Consequently, she "[got] into a teaching rut", that is, "not to be creative in designing teaching activities and not to go outside textbook tasks", which suggests that her teaching approach was less communicative than she imagined. It seems that out-of-work pressures induced study teachers to adopt the GTM.

Negative emotions also predisposed study teachers to use the GTM instead of CLT or TBLT approaches in their classrooms. Stress, disappointment, and tiredness were often reported as a result of teaching struggling students, managing two roles (i.e. teaching and taking care of children), and experiencing physical constraints at work. Study teachers mentioned mainly a teacher-centred approach to teaching as a result of negative emotions. For example, teacher 4 talked and wrote about her "irritated" feeling when next-door teachers requested her to restrain the students from talking too loud. She explained, "How can I teach a speaking activity without encouraging my students to discuss? It is because of the lack of sound proofing of classroom walls, not because of me and my students". The negative experience had such a strong emotional impact on her that it prevented her from implementing future interactive activities in the classroom although she admitted the usefulness of such activities.

\section{DISCUSSION}

Findings from this study have indicated a wide gap that existed between what was believed and what was actually implemented by experienced teachers. Participating teachers valued and were actually aware of the benefits of interactive activities to students' communication skills. However, they adopted teacher-centred, GTM-oriented instruction in the classroom. The inconsistence in belief and action of teachers in the present study elaborates on Parajes' (1992) comment that stated beliefs are an unreliable indicator of actual practice. This finding is similar to what Alghanmi and Shukri (2016), King and Nash (2011), Kuzborska (2011), Mori (2011), and Yang and Gao (2013) found in their studies. However, this finding is inconsistent with findings of Baleghizadeh and Farshchi (2012), Ferreira (2014), Hos and Kekec (2014), Rashidi and Moghadam (2015), and Zheng and Borg (2014) as discussed earlier in the literature review section.

In the present study, a number of reported factors that appeared to compel study teachers to adopt the GTM rather than CLT or TBLT approaches. According to participating teachers, a lot of factors from the environment, e.g. students' factor, traditional educational values and norms, physical working constraints, family roles and from themselves, e.g. emotion, came into play in affecting the belief-practice relationship. The disparities between teachers' stated beliefs and their actual classroom practices can be attributed to a range of cognitive and contextual factors (Cross, 2010). Teachers "make instructional choices by drawing on complex, practically oriented, personalized and context-sensitive networks of knowledge, thought and beliefs" (Borg, 2003). The mismatch between beliefs and practices in the present study highlighted the role of environment in determining behaviour. 
The study highlights certain aspects of Vietnamese culture which appeared to induce study teachers to use the GTM instead of CLT or TBLT approaches in the classroom. The burden of domestic duties and Vietnamese educational values were reported to hinder study teachers' implementation of interactive activities. This finding suggests that teachers' belief-practice relationship should be studied within a framework that is aware of the influence of culture and other local historical contexts. Although teachers' beliefs and behaviors have been the focus of previous investigations, scant attention has been paid to the impact of socio-cultural factors (Nguyen, 2013). This study therefore can be seen as a small step in response to the lack of studies investigating the impact of culture on teachers' belief-practice relationship.

The incongruence between teachers' stated beliefs and their observed classroom behavior under the influence of physical constraints, including syllabus time-frame, class size and student groupings, implies that in order to encourage study teachers to implement CLT or TBLT approaches (behavior), it would be helpful to improve teaching conditions at the university and the faculty. Results from previous studies indicated that when physical conditions of public school facilities and availability of resources are addressed, teacher job satisfaction and performance are improved (Buchanan et al., 2013; Narayan, 2016; Mohammad, 2011).

Findings indicate that teachers' negative emotions mediated the way they behaved in the classroom and predisposed the teachers to adopt the GTM although they did not believe in its effectiveness. Researchers suggest that the positive emotional experiences of teachers are more likely to link with student-centered approaches to teaching while negative feelings go in line with transmission-focused approaches (Postareff \& Lindblom-Ylänne, 2011; Trigwell, 2012). Therefore, improving physical conditions as discussed above can partly decrease types of negative emotions experienced by teachers. However, it is not easy to change long-standing educational and cultural norms in the Vietnamese context. Therefore, it would be helpful to encourage teachers to learn selfregulation strategies (Wheatley, 2002). Learning self-regulation skills might empower teachers to take advantage of negative emotions to get through difficult periods. Coaching teachers to develop strategies to re-tune their thoughts in a favourable manner and to set up plans to approach goals analytically can increase their self-efficacy in enacting communicative activities.

\section{CONCLUSION}

The purpose of this qualitative case study is to explore the belief-practice relationship of a group of university teachers in Vietnam. Findings indicate that different factors from the environment and from the teachers themselves induced the study teachers to adopt the GTM to teach EFL although they did not believe in its effectiveness.

In the present study, there was only one male participant. This sampling limitation might have impacted on data and the interpretation of women's perceived family roles. Further researchers may want to include more male teachers in order to verify or moderate this finding in other contexts. Despite this limitation, this study represents an encouraging attempt to further advance our knowledge of how EFL teachers think and act and how 
we can better bridge the gap between practice and research, particularly in the rarely explored EFL settings. Although findings of this study relate specifically to the Vietnamese context, its implications may be relevant to other educational contexts and to teacher development in general.

\section{REFERENCES}

Alghanmil, B. \& Shukri, N. (2016). The relationship between teachers' beliefs of grammar instruction and classroom practices in the Saudi context. English Language Teaching, 9 (7), 70-86.

Baleghizadeh, S., \& Farshchi, S. (2009). An exploration of teachers' beliefs about the role of grammar in Iranian high schools and private language institutes. Journal of English Language Teaching and Learning, 52 (212), 17-38.

Barrot, J. S. (2016). Examining the teaching beliefs and practices of experienced ESL teachers: A sociocognitive-transformative perspective. $3 L$ : The Southeast Asian Journal of English Language Studies, 22(1), 153-163.

Borg, S. (2003). Teacher cognition in language teaching: A review of research on what language teachers think, know, believe, and do. Language Teaching, 36(02), 81-109.

Borg, S. (2009). Language teacher cognition. In A. Burns \& J. C. Richards (Eds.), The Cambridge guide to second language teacher education (pp. 163-171). Cambridge: Cambridge University Press.

Brown, H. D. (2007). Teaching by principles: An interactive approach to language pedagogy. White Plains, N.Y: Pearson Education.

Buchanan, J., Prescott, A., Schuck, S., Aubusson, P., Burke, P., \& Louviere, J. (2013). Teacher retention and attrition: Views of early career teachers. Australian Journal of Teacher Education, 38(3), 112-129.

Cheng, X., \& Moses, S. (2011). Perceptions and implementation of task-based language teaching among secondary schools EFL teachers in China. International Journal of Business and Social Science, 2(24), 292-302.

Creswell, J. W. (2012). Educational research: planning, conducting, and evaluating quantitative and qualitative research (4th ed.). Boston: Pearson.

Cross, R. (2010). Language teaching as sociocultural activity: Rethinking language teacher practice. The Modern Language Journal, 94(3), 434-452.

Ellis, R. (2003). Task-based language learning and teaching. Oxford, U.K: Oxford University Press.

Ferreira, P. (2014). Beliefs and practices towards teaching and learning grammar: A multicase study. Bellaterra Journal of teaching and learning language and literature, 7(3), 14-29. 
Farrell, T.S.C., \& Bennis, K. (2013). Reflecting on ESL teacher beliefs and classroom practices: A case study. RELC Journal, 44(163). doi:10.1177/0033688213488463

Hos, R., \& Kekec, M. (2014). The mismatch between non-native English as a Foreign Language (EFL) teachers' grammar beliefs and classroom practices. Journal of Language Teaching and Research, 5(1), 80-87. http://dx.doi.org/10.4304/jltr.5.1.80-87

King, C. H., \& Nash, C. P. (2011). Bilingual Teacher Beliefs and Practice: Do They Line Up. Gist Education and Learning Research Journal, 5, 66-83.

Kuzborska, I. (2011). Reading between teachers' beliefs and practices and research on reading. Reading in a Foreign Language, 23(1), 102-128. Retrieved May 25, 2017 from http://nflrc.hawaii.edu/rfl/April2011/articles/kuzborska.pdf

Le, V. C. (2011). Form-focused instruction: A case study of Vietnamese teachers' beliefs and practices. (Doctoral thesis). University of Waikato. Retrieved from http://researchcommons.waikato.ac.nz/handle/10289/5253

Lincoln, Y. S., \& Guba, E. G. (1985). Naturalistic inquiry. Newbury Park, CA: Sage.

Littlewood, W. (2007). Communicative and task-based language teaching in East Asian classrooms. Language Teaching, 40(03), 243-249. doi:10.1017/S0261444807004363

Mohammad, A. (2011). Job satisfaction of secondary school teachers: A comparative analysis of gender, urban and rural schools. Asian Social Science, 7(8), 203-208. http://doi.org/10.5539/ass.v7n8p203

Mori, R. (2011). Teacher cognition in corrective feedback in Japan. System, 39(4), 451467.

Nguyen, G. V. (2013). Orienting to pedagogical innovation: A case study of Vietnamese teachers' beliefs and practices regarding Task-based Language Teaching (Doctoral thesis). University of Waikato. Retrieved from https://hdl.handle.net/10289/7433

Narayan, N. A. (2016). Factors influencing teacher career satisfaction, teacher collaboration and everyday challenges: An exploratory factor analysis, Malaysian Online Journal of Educational Sciences, 4(3), 24-38.

Pajares, F. (1992). Teachers' beliefs and educational research: Clearing up a messy construct. Review of Educational Research, 62(2), 307-332.

Phan, N. T. T. (2015). Can I teach these students? A case study of Vietnamese teachers' self-efficacy in relation to teaching English as a foreign language (Doctoral thesis). University of Waikato. Retrieved from http://hdl.handle.net/10289/9433

Postareff, L., \& S. Lindblom-Ylänne. 2011. Emotions and confidence within teaching in higher education." Studies in Higher Education, 36 (7), 799-813

Phan, H. L. (2004). University classrooms in Vietnam: Contesting the stereotypes. ELT Journal, 58(1), 50-57. 10.1093/elt/58.1.50 
Phan, H. T. T. (2011). Factors affecting the motivation of Vietnamese technical English majors in their English studies (Doctoral dissertation). The University of Otago, Dunedin. Retrieved from http://otago.ourarchive.ac.nz/handle/10523/652

Rahman, M. M., Singh, M. K. M., \& Pandian, A. (2018). Exploring ESL teacher beliefs and classroom practices of CLT: A case study. International Journal of Instruction, 11(1), 295-310. https://doi.org/10.12973/iji.2018.11121a

Rashidi, N., \& Moghadam, M. (2015). The discrepancy between teachers' belief and practice from the Sociocultural Perspective. Studies in English Language Teaching, $3(3), 252-274$.

Shanina, S.A.S. (2014). Secondary school ESL teachers' beliefs and practices in the teaching of pronunciation. (Unpublished doctoral dissertation), University Malaya, Malaysia.

Stake, R. E. (2010). Qualitative research: Studying how things work. New York: Guilford Press.

Tomlinson, B., \& Dat, B. (2004). The contributions of Vietnamese learners of English to ELT methodology. Language Teaching Research, 8(2), 199-222. 10.1191/1362168804lr140oa

Trigwell, K. 2012. "Relations between teachers' emotions in teaching and their approaches to teaching in higher education." Instructional Science, 40 (3), 607-621.

Wheatley, K. F. (2002). The potential benefits of teacher efficacy doubts for educational reform. Teaching and Teacher Education, 18(1), 5-22. http://dx.doi.org/10.1016/S0742051X(01)00047-6

Yang, L., \& Gao, S. (2013). Beliefs and practices of Chinese university teachers in EFL writing instruction. Language Culture and Curriculum, 26(2), 128-145.

Zheng, X. \& Borg, S. (2014). Task-based learning and teaching in China: Secondary school teachers' beliefs and practices. Language Teaching Research, 18(2), 205-221. 